
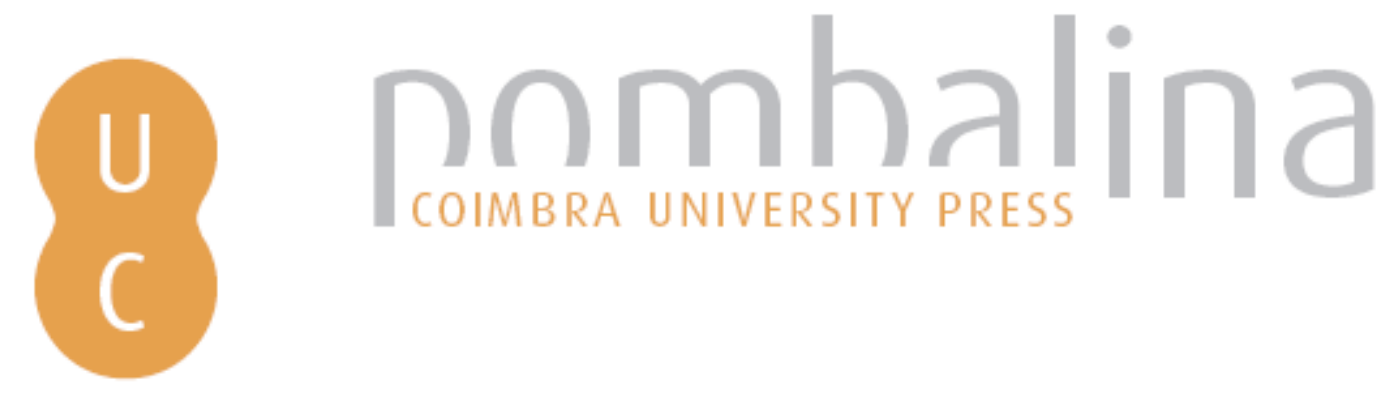

\title{
Logomaquia e a crítica à retórica democrática ateniense em Tucídides
}

\author{
Autor(es): $\quad$ Soares, Martinho
}

Publicado por: Imprensa da Universidade de Coimbra

URL

persistente: URI:http://hdl.handle.net/10316.2/45148

DOI: $\quad$ DOl:https://doi.org/10.14195/978-989-26-1679-7_4

Accessed : $\quad$ 26-Apr-2023 12:59:34

A navegação consulta e descarregamento dos títulos inseridos nas Bibliotecas Digitais UC Digitalis, UC Pombalina e UC Impactum, pressupõem a aceitação plena e sem reservas dos Termos e Condições de Uso destas Bibliotecas Digitais, disponíveis em https://digitalis.uc.pt/pt-pt/termos.

Conforme exposto nos referidos Termos e Condições de Uso, o descarregamento de títulos de acesso restrito requer uma licença válida de autorização devendo o utilizador aceder ao(s) documento(s) a partir de um endereço de IP da instituição detentora da supramencionada licença.

Ao utilizador é apenas permitido o descarregamento para uso pessoal, pelo que o emprego do(s) título(s) descarregado(s) para outro fim, designadamente comercial, carece de autorização do respetivo autor ou editor da obra.

Na medida em que todas as obras da UC Digitalis se encontram protegidas pelo Código do Direito de Autor e Direitos Conexos e demais legislação aplicável, toda a cópia, parcial ou total, deste documento, nos casos em que é legalmente admitida, deverá conter ou fazer-se acompanhar por este aviso. 

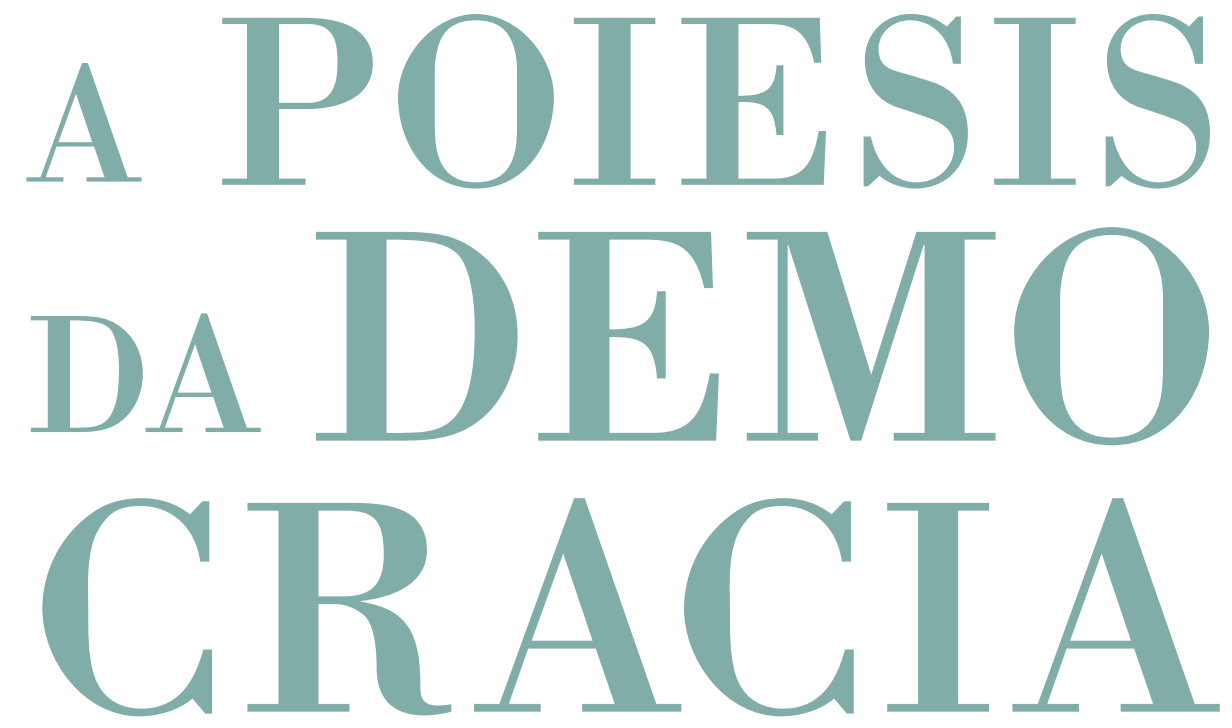

G

Breno Battistin Sebastiani, Delfim Leão,

Lugia Sano, Martinho Soares, Christian Werner

\section{CoimbraCompanions}




\title{
Logomaquia
}

E A CRÍticA À RETÓRICA DEMOCRÁtiCA ATENIENSE EM TUCÍDIDES

\section{LOGOMACHY}

\begin{abstract}
AND THE CRITICISM OF THE ATHENIAN DEMOCRATIC RHETORIC ON THUCYDIDES
\end{abstract}

Martinho Soares

Universidade Católica Portuguesa

ORCID | 0000-0001-8153-2014 


\section{Resumo}

As críticas de Tucídides contra o sistema democrático ateniense centram-se de modo particular na denúncia das fragilidades do debate oratório, instrumento privilegiado da dialética democrática. A natureza retórica da linguagem, os interesses ocultos e a má formação dos oradores, a suscetibilidade do auditório, são alguns dos problemas levantados pelo próprio Tucídides, que ganham ressonância nas vozes de Péricles, Cléon e Diódoto. Aqui analisamos as oposições, convergências e especificidades das críticas veiculadas por cada uma destas vozes, alinhadas pela preocupação fundamental da procura da verdade.

\section{Palavras-chave}

Tucídides, democracia, historiografia, oratória, retórica 


\section{Abstract}

Thucydides' criticisms of the Athenian democratic system are particularly focused on denouncing the weaknesses of the oratory debate, a privileged instrument of democratic dialectics. The rhetorical nature of language, hidden interests, speakers' lack of education and susceptibility of the audience, are some of the problems raised by Thucydides himself, which resonate in the voices of Pericles, Cleon, and Diodotus. Here we analyze the oppositions, convergences and specificities of the criticisms conveyed by each of these voices, aligned with the fundamental concern of the search for truth.

\section{Keywords}

Thucydides, Democracy, Historiography, Oratory, Rhetoric 


\section{INTRODUÇÃO}

Pretendemos com este trabalho pôr em evidência a crítica democrática levada a cabo por Tucídides, partindo não de comentários que o mesmo tenha tecido de forma direta na sua obra contra as instituições e a constituição democráticas atenienses ${ }^{1}$, mas por via da crítica a um dos instrumentos privilegiados da democracia ateniense: o debate oratório ${ }^{2}$. Paralelamente, a análise de alguns passos selecionados da História da Guerra do Peloponeso fará emergir uma solução para os problemas retóricos detetados pelo historiador; porá a descoberto aparentes contradições da meta-crítica tucididiana, patentes sobretudo na discrepância entre forma e conteúdo; revelará a que ponto os discursos político-retóricos construídos por Tucídides são um testemunho muito nítido e envolvente do ambiente democrático ateniense e do seu caráter dialético. A nossa apresentação terá três etapas distintas mas interligadas. Numa primeira fase caracterizaremos sucintamente o combate oratório na História da Guerra do Peloponeso e na polis democrática ateniense, pondo em relevo o papel dos discursos e a sua articulação com a narrativa; numa segunda, explanaremos a crítica à retórica democrática, recorrendo a testemunhos textuais da obra tucididiana; por fim, sumariaremos as principais conclusões inferidas da análise.

1 Sobre as críticas diretas de Tucídides ao sistema democrático ateniense, vide Raaflaub 2006.

2 Seguimos na senda aberta por Greithlein (2013: 127): "Oratory forms an interesting link between democracy and historiography"; e Yunis (2013: 156): "criticism of Athenian democracy often focused on democratic rhetoric". Vide etiam Yunis 1996 e 1998. 
Quase um terço da História da Guerra do Peloponeso de Tucídides é preenchida com peças de oratória: contam-se vinte e seis discursos políticos, incluindo debates, e um diálogo. Estes conferem um enorme colorido à obra, ao mesmo tempo que expõem com vividez e intensidade dramática os pontos de vista e os preconceitos, as esperanças e os receios, os planos, as ideias, as fraquezas e as virtudes dos intervenientes. Ao introduzir a oratória na historiografia, Tucídides não só transpõe para o universo da escrita um hábito social oral muito em voga na Atenas democrática do seu tempo, o agon logon ou debate oratório, como dá continuidade a uma tradição poética de matriz homérica³. Com efeito, os poemas homéricos foram os primeiros a concatenar discurso e narrativa, dando início a uma prática levada depois por Heródoto para a Historiografia, e pelos dramaturgos para a Tragédia e para a Comédia, géneros em que os confrontos verbais se constituem como os grandes estruturadores da intriga.

As relações diplomáticas entre as várias cidades-estado desempenham um papel axial na economia da História da Guerra do Peloponeso, exteriorizando-se estas nos discursos com os quais as várias poleis procuram justificar e clarificar as suas posições. O conflito dialético entre diplomatas ou embaixadores das poleis é o melhor exemplo do chamado realismo político, do qual Tucídides é tido por precursor ${ }^{4}$. Todavia, na História da guerra do Peloponeso pontua ainda um outro tipo de discursos: os que os estrategos dirigem aos seus concidadãos e os chefes militares aos seus soldados. Trata-se de exortações ou de arengas que permitem perceber melhor o curso dos acontecimentos e fornecem informações úteis aos leitores 5 . Discursos deliberativos e diplomáticos permitem ambos a exposição

3 Sobre a diferença entre retórica política e retórica literária, vide Yunis 2013. Sobre os discursos de Tucídides há uma extensa bibliografia, dentro da qual salientamos apenas alguns títulos fundamentais: Moraux 1954; Stadter 1973, Woodman 1988; Tsakmakis 2006 e 2017; Morrison 2006; Scardino 2007; Marincola 2008; Iglesias-Zoido 2008 e 2011: 51-73.

4 Vide Kemos 1994 e Nogueira 2000.

5 Acerca dos discursos militares na obra de Tucídides, vide Hansen 1993, Iglesias-Zoido 2006, 2007, 2008a, 2011: 64-68. Lendon 2017 apresenta uma muito completa lista bibliográfica 
de motivações diversas com vista a persuadir o auditório para uma determinada causa em detrimento de outra, pondo de manifesto "uma

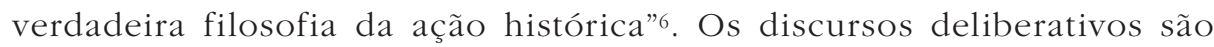
particularmente significativos no modo como exibem o confronto de opiniões de oradores que defendem o interesse de uma mesma cidade. Cléon e Diódoto, Alcibíades e Nícias por Atenas, Arquidamo e Estenelaidas por Esparta, Hermócrates e Atenágoras por Siracusa representam pontos de vista opostos, que põem a descoberto sentimentos e razões amiúde incompatíveis. Não raras vezes, estes debates têm como finalidade mostrar quem consegue persuadir e mobilizar os seus concidadãos para uma de duas estratégias: uma tendencialmente mais moderada, que apela à paz, outra mais radical, que apela à guerra e à violência.

A composição dos debates em Tucídides obedece a um método intelectual preciso, ao qual não é alheia a metodologia estabelecida por Protágoras para a antilogia: primeiro, para qualquer questão existem sempre dois discursos ou pontos de vista; segundo, a arte da discussão consiste em encontrar argumentos para contradizer o adversário procurando ser mais convincente. A antilogia era uma forma privilegiada de sabedoria e compreensão entre os Gregos, que tinham por hábito não tomar partido sem ouvir as duas teses em litígio, os prós e os contras, preferindo a pluralidade à unilateralidade.7

Os discursos evidenciam, pois, o ambiente cultural da polis de Tucídides, a Atenas do séc. V a.C., com os seus tribunais e assembleias, palcos de incessantes logomaquias ${ }^{8}$. Com a introdução da democracia no espaço

sobre a questão dos discursos militares na historiografia antiga, com destaque para o modelo exortativo praticado por Tucídides.

6 Châtelet 1962: 228.

7 Hannah Arendt (2006: 65) enaltece precisamente os discursos como reflexo do modelo democrático vivido na polis ateniense, qualificando esta forma de apresentar os factos como um "poderoso elemento" de objetividade histórica: “Os Gregos aprenderam a compreender - não a compreenderem-se uns aos outros enquanto indivíduos, mas a olhar para um mesmo mundo a partir da posição do outro, a ver a mesma coisa sob perspetivas muito diferentes e frequentemente antagónicas. Os discursos nos quais Tucídides expõe as posições e os interesses das partes em conflito constituem ainda um testemunho vivo do extraordinário alcance desta objetividade".

8 Sobre a participação política e o seu desenvolvimento na democracia ateniense, vide Sinclair 1988; acerca do papel fundamental da retórica no sistema democrático, vide Ober, 
ateniense dá-se a chamada "laicização da palavra" . Os cidadãos atenienses puderam usar livremente da fala para questionar e investigar toda a realidade com a luz da razão. Os discursos tucididianos provam justamente a familiaridade do escritor com estas novas ideias. É preciso entender que na génese das disputas verbais e da própria historiografia se encontra uma causa comum, a democracia, e que a obra de Tucídides, ao introduzir os discursos políticos, assume-se como o espelho da sua própria génese e da sua própria época ${ }^{10}$. A vida política e o assumir do estatuto político pelo homem grego contribuem para uma tomada de consciência da existência humana como existência sensível-profana e como devir efetivo, onde se dão acontecimentos que vale a pena anotar e apresentar às gerações futuras ${ }^{11}$.

Deixar os protagonistas falar foi a forma que os historiógrafos gregos encontraram para fazer o leitor ou o ouvinte assistirem ao passado sem terem que intervir com comentários ou análises. No caso de Tucídides, observa-se que os discursos desempenham uma função explicativa, revelam o vínculo que o historiador estabelece entre a política e a ação histórica, implicando, desse modo, o sacrifício da objetividade material em favor da verdade de conjunto ${ }^{12}$. Para Romilly, os discursos são "verdadeiros modelos de previsão"13, na medida em que mostram os oradores operando em antecipação, isto é, raciocinando no sentido de perspetivar o futuro desenvolvimento dos acontecimentos. Assim sendo, os combates descritos por Tucídides tanto confirmam como desmentem os cálculos e as previsões dos estrategos, sem que ele tenha de julgar ou comentar. Por este meio, compreendemos porque é que Atenas, Esparta, Corinto, Nícias, Demóstenes agiram da forma como agiram em determinada circunstância: perante uma

1993 e 1998; Lanni 2013, para além dos autores referidos na nota 3.

9 Detienne 2006: 10

10 Yunis 1996, 1998.

11 Châtelet 1962: 82-83. Meier (1980; 1987) também associa a emergência da historiografia à implantação do regime democrático, avocando uma série de causas; Grethlein (2013) não desmente essa associação, mas põe a ênfase na necessidade que a oratória democrática, muito bem traduzida nos epitaphioi logoi ou orações fúnebres, teve de evocar exempla do passado.

12 Romilly 2005: 35 .

13 Ibid.: 17. 
certa conjuntura e em vista de um determinado fim - independência, vitória - quase evidente, a decisão resulta de um cálculo ${ }^{14}$.

Na senda de Romilly, também Virginia Hunter reconhece nos discursos tucididianos a faculdade de concentrar a narrativa em torno de um tema central e a capacidade de antecipar acontecimentos que a narrativa posterior virá iluminar. Hunter acrescenta ainda que a conexão dos discursos com os factos narrativos não se faz só para diante mas também para trás, mostrando se o falante aprendeu alguma coisa com experiências anteriores, suas ou de outros ${ }^{15}$. Hunter verifica que não só os oradores e os ouvintes aprendem com os modelos do passado (paradeigmata), mas o próprio leitor é instigado a distinguir a verdade da ficção dos discursos, na medida em que viu como os acontecimentos posteriores deram ou não razão aos cálculos probabilísticos dos oradores, corroborando ou frustrando as suas expectativas e na medida em que é instruído a aprender com a empeiria do passado. Para o leitor, a História de Tucídides representa então um repositório de experiências: experiências de vida e experiências metodológicas que o ajudarão a orientar melhor a sua ação, prevendo perigos, prevenindo más decisões, evitando o dolo dos logoi, discernindo a verdade. Em boa verdade, este método está em linha com o topos ciceroniano da historia magistra vitae, ao qual René Koselleck dará uma considerável amplitude filosófica ${ }^{16}$.

A análise da influência da disciplina retórica no texto de Tucídides contribuiu para aprofundar enormemente a nossa compreensão dos discursos. Foram postos a descoberto vários paralelismos entre os discursos proferidos pelas personagens tucididianas e os proferidos pelos praticantes e teóricos da retórica grega: sofistas, tragediógrafos, autores de oratória forense, diálogos filosóficos e manuais de retórica ${ }^{17}$. O historiador grego - tudo leva a crer - conheceria bem os tratados de oratória que circularam pela Atenas do século V, nomeadamente, os ensinamentos de Górgias e de outros sofistas

14 Também Aron (1961: 16), sintonizando com Romilly (1956), salienta a inteligibilidade dos combates e dos acontecimentos bélicos pela sua interrelação com os planos dos estrategos. Vide etiam Morrison 2006.

15 Hunter 1982: 291-293. Cf. Marincola 2008: 130-132.

16 Koselleck 1990.

17 Vide Hornblower 1987: 45-72 e 110-131; Cole 1986, 1991. 
e oradores, de quem nos chegaram pouco mais do que fragmentos ${ }^{18}$. Finley foi o primeiro a demonstrar a que ponto o historiador foi fiel ao pensamento e à arte retórica da sua época, comparando os discursos da História da Guerra do Peloponeso com as primeiras peças de Eurípides ${ }^{19}$. As ideias e o estilo argumentativo, conhecido como formal, que Tucídides põe na boca dos seus falantes, é o mesmo que é empregado nas tragédias euripidianas. A argumentação formal ensinada por Górgias, praticada por Antifonte e criticada por Sócrates no Fedro de Platão consistia exatamente num vademecum de lugares-comuns argumentativos. Logo, há motivos para acreditar que Tucídides pôs os oradores a falar em consonância com um determinado número de regras fixas de retórica e linhas de argumentação que os próprios oradores deveriam conhecer e usar. Verifica-se que a expressão empregada por Tucídides, ta deonta malist' eipein (Thuc. 1. 22. 1), é muito próxima e tem o mesmo significado daquela que Sócrates refere no Fedro (234e6) para caracterizar o velho tipo de argumentação formal: os ta deonta malist' eirekotos. O facto de esta oratória ser em grande medida convencional torna credível que os discursos de Tucídides fossem simultaneamente criação sua e ao mesmo tempo refletissem formas de pensamento e de argumentação amplamente utilizados pelos seus contemporâneos ${ }^{20}$.

Apesar de assentar os discursos nas calhas da sofisticada arte retórica do seu tempo, Tucídides revela-se um crítico constante do poder retórico e enganador da oratória, pelos prejuízos que o seu mau uso pode acarretar para a polis ateniense, como se comprova na desastrosa expedição à Sicília. É sobre esta metacrítica retórica e historiográfica que iremos centrar a nossa

18 Estes tratados (technai) que circulariam pela Atenas do séc. V, mais do que exposições teóricas, seriam sobretudo compilações de exemplos oratórios. Só no séc. IV apareceriam tratados teóricos de oratória mais elaborados, como a Retórica a Alexandre, atribuído a Anaxímenes de Lâmpsaco, e a Retórica de Aristóteles. Os próprios discursos de Tucídides terão servido como exemplos paradigmáticos para o desenvolvimento da normativa retórica do séc. IV. Vide Iglesias-Zoido 2011: 62-63.

19 Finley 1967.

20 Vide Hammond 1973, Mcleod 1975. Sobre a muito debatida e polémica questão da veracidade histórica dos discursos não nos alongamos aqui, remetendo os interessados para as seguintes leituras: Gomme 1954, Finley 1967, Cogan 1981, Hornblower 1987, Woodman 1988; Brunt 1993, Swain 1993, Várzeas 2004, Soares 2014: 462-476, Iglesias-Zoido 2011: 5159. 
atenção na próxima secção deste nosso estudo, partindo para tal de uma série de textos significativos, extraídos da História da Guerra do Peloponeso.

\section{A METACRÍTICA HISTORIOGRÁFICA: FRAGILIDADES DA RETÓRICA POLÍTICA E DO GOVERNO DEMOCRÁTICO ATENIENSE}

Isto foi o que eu descobri acerca dos tempos antigos, sendo difícil confiar em qualquer prova deixada. Com efeito, as pessoas aceitam indistintamente e sem provas $\mathrm{O}$ que ouvem umas das outras sobre os acontecimentos do passado, mesmo que seja do seu próprio país. [...] Descuidada é para muitos a busca da verdade, e preferem

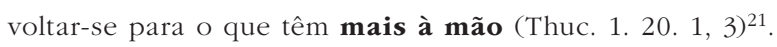

O comentário acima transcrito, que serve de proémio a um conjunto de declarações de teor metodológico, confinadas entre os capítulos 20 e 22, é rematado com o ilustrativo caso do assassinato de Hiparco por Aristogíton e Harmódio, ocorrido em 514 a.C.. O historiador reprova justamente a receção acrítica (omoios) e infundada (abasanistos) do passado, pois os Atenienses na sua maioria acreditam que Hiparco era tirano aquando do seu assassinato, quando na verdade quem governava era seu irmão Hípias, filho mais velho do falecido tirano Pisístrato. Tal não impediu que os dois conjurados viessem a ser heroicizados como tiranicidas nas múltiplas representações verbais e materiais de glorificação patriótica do regime democrático, associando-se o seu feito ao fim da tirania e à passagem à democracia22. Tucídides, que acabava de fazer uma digressão históricoarqueológica pelos tempos mais antigos (ta palaitera - Thuc. 1. 1. 2), conjeturando com base em provas e indícios (ek de tekmerion) ${ }^{23}$, conclui

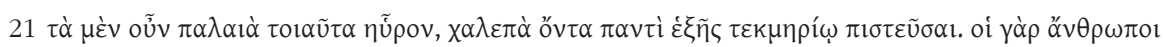

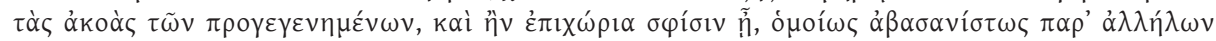

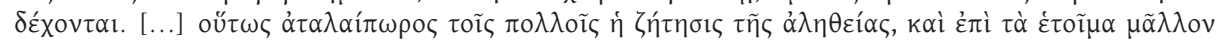

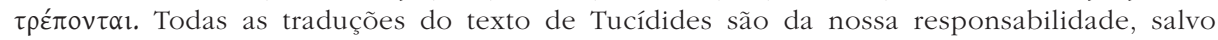
indicação contrária, e são feitas a partir da edição de Jones \& Powell 1942 (reimp. 1963).

22 Tucídides relata mais detalhadamente o ocorrido em 6. 54-59. Para um estudo aprofundado deste assunto, vide a análise de Nuno Simões Rodrigues neste volume.

23 A secção conhecida como Arqueologia, que integra os capítulos iniciais da obra, é um caso à parte na História da Guerra do Peloponeso, na medida em que constitui o único 
com o comentário meta-histórico acima transcrito, onde basicamente apresenta a sua metodologia como exemplar para qualquer investigação rigorosa sobre o passado, a qual fundamentalmente deverá assentar em provas (tekmeria) e jamais em boatos ou no diz-que-disse (tas akoas). Depois de apresentar mais alguns exemplos denunciadores da aceitação equívoca do passado, avança para um novo bloco de reflexões metodológicas que preenchem os capítulos 21 e 22. Retomemos ainda a ponta solta do capítulo 20.

"Descuidada é para muitos a busca da verdade (zetesis tes aletheias), e preferem voltar-se para o que têm mais à mão" (Thuc. 1. 20. 3). Não é assim para Tucídides. Salta à vista, pela insistência, o desejo de rejeitar tudo o que não possa ser comprovado e tudo o que só serve para embelezar e engrandecer discursos destinados à declamação.

No entanto, quem, tendo em conta as provas mencionadas, considerasse as coisas que eu expus, não se equivocaria, não daria tanto crédito ao que os poetas compuseram acerca delas embelezando-as ao máximo, nem aos logógrafos, que escreveram acerca delas mais para agradar a a auditório do que para fins de verdade, pois, sendo coisas impossíveis de comprovar, muitas delas, devido ao tempo transcorrido, passaram de forma não fiável para o domínio do fabuloso; por fim,

segmento dedicado por inteiro à história do passado e é a única secção em que temos acesso à oficina do historiador: vemos Tucídides a selecionar informações, a submetê-las à análise lógica e a reconstruir um período do qual não teve conhecimento direto nem testemunhal, aproximando-se muito do papel arcaico do histor. Por isso mesmo, Tucídides vê-se na obrigação de estabelecer um método diferente para o estudo desta época remota, cujo conhecimento considera difícil: "Na verdade, não era possível conhecer com clareza o que aconteceu antes nem os acontecimentos ainda mais antigos por se ter passado um longo período de tempo, mas a partir dos indícios nos quais se baseia a minha confiança, quando procuro ver até onde é possível alcançar, considero que não houve nada de grandes dimensões nem em guerras nem noutras coisas (Th 1. 1. 2)." Enquanto baseia a sua reconstrução do presente numa coleção de experiências pessoais e entrevistas, o período histórico da Grécia Arcaica é reconstruído com base em conjeturas e indícios (ek de tekmerion) - retirados da poesia épica, tradições locais, escavações tumulares, observação de monumentos do período heroico - que eram do conhecimento público. Tucídides não descreve o passado como descreve o presente. Alterna entre a certeza no que diz - "é claro" (phainetai); as deduções pessoais - "parece-me" (dokei moi); as probabilidades - "como parece provável" (os eikos); e a conjetura - (eikazein de chre). Pelo seu caráter exemplar e demonstrativo, Crane considera a Arqueologia um exercício epidíctico semelhante aos dos oradores: vide Crane 1996: 32 e Nicolai 2001. 
não se equivocaria quem considera que se investigou suficientemente, tendo em conta a antiguidade dos factos, a partir dos indícios mais evidentes (Th 1. 21. 1) 24 $^{2}$

Trata-se de contrapor a falta de credibilidade da poesia e da oratória à fiabilidade do relato tucididiano, assente em provas, conceito que ganha aqui um novo significante: ao lado de tekmeria surge agora, com o mesmo valor semântico, semeia. São as provas que permitem evitar o equívoco (hamartano). Provas e confiança (pistis) - o autor usa o verbo pisteuo situam-se claramente do lado do relato historiográfico e da verdade; em contrapartida, fantasia (mythodes) e falta de fiabilidade (apistos) situam-se do lado de poetas e logógrafos, os quais compõem discursos belos, mas não necessariamente verdadeiros, mais preocupados em cativar (prosagein) o auditório (akroasis) do que em transmitir a verdade dos factos.

Em parte, o significado do conceito mythodes seria facilmente percetível, devido à óbvia raiz etimológica, mas o seu alcance semântico não está totalmente definido. Algo que tem que ver com o mito, mas não é mito, antes à maneira de mito? Referir-se-á a histórias de caráter fabuloso, que se assemelham a mitos sem serem mitos, ou seja, como eles fabulosos, indemonstráveis e verosímeis, para agradar aos ouvintes ${ }^{25}$ ? Stewart Flory26 associa o conceito a uma forma de exaltação ou enaltecimento nacionalista, significando em Tucídides histórias patrióticas, o que vai bem com a crítica à oratória deliberativa e epidíctica, se considerarmos a sua apetência pelo

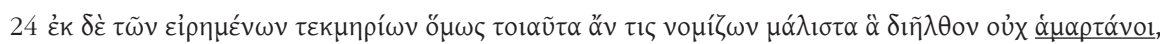

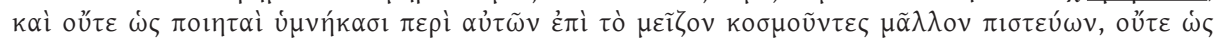

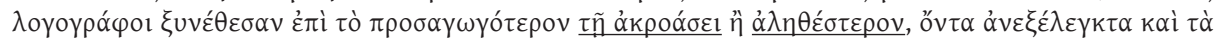

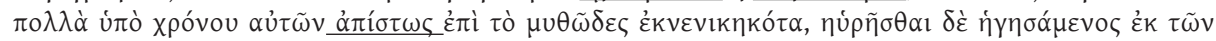

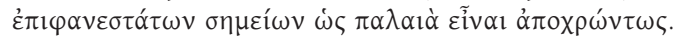

25 «Now there is a general consensus that by the mythic (to mythodes) Thucydides meant the fabulous or storytelling element of his predecessors. He contrasts it with clarity (to saphes), which seems to be closely bound up with the certainty of contemporary history, and this suggests that 'the mythic' cannot be tested or inquired about, because of both the distance in time from the events, and the essentially fantastic nature of the material. It is a tribute to the influence of Thucydides that after him myth could only with difficulty be rescued or redeemed. In later historians we can see only three possibilities: avoid myths altogether; try to 'rationalize' or 'de-mythologise' them; or, as Lucian suggests, include them, but leave their credibility to the reader to decide. If one include them, one had to defend oneself» (Marincola 1997: 117-118).

26 Flory 1990. 
colorido dos episódios históricos nacionais. O que podemos ter por certo é a predileção de poetas e logógrafos por este tipo de artifício retórico.

Quanto aos logógrafos, tem sido posta em causa tanto a convicção nunca confirmada de Dionísio de Halicarnasso (De Thuc. 5), que apontava para uma espécie de genealogistas ou historiadores anteriores a Heródoto, como a que os identifica com prosadores, indivíduos que se dedicariam à recolha e transcrição de logoi, no sentido de histórias orais, entre os quais se contaria o próprio Heródoto. De acordo com investigações mais credíveis, quer os consideremos simples redatores de discursos para outros ${ }^{27}$ ou mesmo pronunciadores de discursos, podemos facilmente inclui-los na categoria de oradores ${ }^{28}$.

Tucídides acusa-os de cederem ao prazer do auditório, agindo em função do curto momento das suas performances públicas. O historiador ateniense não pretende ser agradável ao ouvido, somente ser útil, por isso recusa narrar acontecimentos de caráter fabuloso ${ }^{29}$. Em contraponto com a fugacidade da oralidade (to parachrema akouein), Tucídides coloca a perenidade da sua lição para sempre (ktema es aiei).

Provavelmente, o caráter não fabuloso dos factos relatados fá-los-á parecer menos

agradáveis ao ouvido: mas julgue-os úteis quantos queiram ver claro nos acontecimentos do passado e nos que, no futuro, em virtude do caráter humano que é o seu, apresentarão similitudes ou analogias, e isso para mim será suficiente. Compôs-se um legado para sempre mais do que uma competição para um auditório momentâneo (Thuc. 1. 22. 4) $)^{30}$.

27 Lavency 1964 e Wolff 2007.

28 Grethlein 2013: 127-128. Sobre esta complexa e polémica questão, vide a recensão bibliográfica apresentada por Grethlein 2013: 127-128 e 137, nota 7. Cf. Corcella 2006.

29 "À la séduction de la parole qui passe, Thucydide oppose son propre choix: être simplement et durablement vrai" (Hartog 2005 : 93). Sobre a relação de Tucídides com o prazer proveniente das palavras, vide a reflexão de Crane 1996: 215-235.

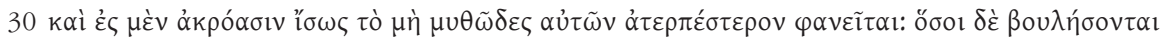

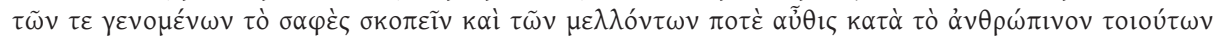

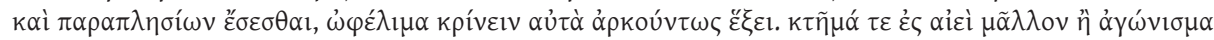

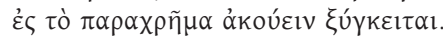


Este excerto que encerra o bloco metodológico traça a linha definitiva que, para o historiador, separa prazer (terpsis), oralidade e audição de um lado e utilidade, escrita e visão do outro. Constata-se a mesma insistência no caráter não fabuloso (to me mythodes) do seu discurso por oposição à competição oratória, aqui identificada com o termo agonisma ${ }^{31}$. A reconhecível mudança do ouvido para o olho operada por Tucídides tem como causa a desconfiança relativamente à ambiguidade retórica e persuasiva do debate oratório. A escrita é o móbil que permite operar esta transferência da audição (akoue) para a visão (opsis e autopsia), por consentir uma atitude crítica e reflexiva que a oralidade, sujeita que está aos limites do imediato e da fugacidade, não atinge ${ }^{32}$. Através da escrita, incluindo a escrita dos discursos, Tucídides estabelece uma epistemologia que pretende ensinar os seus leitores a separar o logos da doxa e a fazer uma pesquisa mais rigorosa da verdade ${ }^{33}$. Efetivamente, como já antes tivemos oportunidade de demonstrar, a verdade é uma preocupação central em Tucídides ${ }^{34}$. Todavia, regressemos às declarações do autor e atentemos na utilidade e no valor intemporal que o mesmo outorga ao seu trabalho, com base na visão clara (saphes skopein) que os leitores lograrão dos factos do passado e dos que poderão vir a ocorrer no futuro. Aqui mais uma vez, o confronto latente com o agon logon, pois que era função do bom orador político mostrar com nitidez os factos do passado para melhor precaver e planear o futuro, o que exigiria uma boa cultura histórica e rigor (akribeia) de pesquisa, algo que Tucídides tem, mas a maioria dos oradores descura, preferindo dissimular essa carência

31 Acerca do significado de agonisma, vide Marincola 2005.

32 Episódio bem sintomático deste conflito entre oralidade e escrita encontra-se em Thuc. 7. 8. 2, quando Nícias recusa confiar nos seus próprios mensageiros devido à falibilidade da oralidade e da memória, optando por escrever uma carta.

33 "For writing allowed one not only to compose and recompose but to study, correct, and revise, dwelling at length and in private on one's manuscript until the eye was satisfied with is product. It permitted "a different kind of scrutiny of current knowledge, a more deliberate sorting of logos from doxa, a more thorough probing into the 'truth' ". The result is a manuscript that yields far more to the eye than to the ear, for the reader could study it closely and discern what the equally close attention of the writer had implanted therein. He would discover an epistemology. And this Thucydides effected through a skillful and original use of one of the conventions of the oral performance since Homer, the speeches of the participants" (Hunter 1982: 290). Vide etiam Yunis 2013: 155-156.

34 Soares 2014. Vide etiam Romilly 1990, Moles 2003, Sebastiani 2017. 
com o efeito retórico-estético-hedónico da linguagem. Não que Tucídides considere a oratória dispensável ou mesmo prejudicial à democracia; pelo contrário, o discurso fúnebre epidíctico proclamado por Péricles no fim do primeiro ano de guerra, como forma de homenagear os falecidos em combate e elogiar a experiência democrática ateniense, afirma categoricamente a importância da oratória para a ação política.

O estadista começa por justificar a oração fúnebre, relembrando a sua instituição e tradição na polis, mas também a dificuldade de manter um discurso equilibrado, quando o estabelecimento da verdade (e dokesis tes aletheias) é difícil de se fazer com segurança (Thuc. 2. 35. 2). Difícil é também não pressentir neste apelo à moderação discursiva e à verdade a voz metacrítica do próprio Tucídides. O que se passa, segundo Péricles, é que alguns ouvintes, conhecedores dos factos, acharão o elogio fúnebre aquém do merecido; outros, desconhecedores, por inveja, tenderão a ver nele exageros. Cada um só aceita os elogios de feitos que ele próprio considera estarem ao seu alcance. O que vá para além disso suscita inveja e incredulidade. Em seguida, o líder ateniense louva inequivocamente o debate público e reconhece as suas virtudes, assinalando um tema caro a Tucídides, herdado da Sofística grega e transversal a toda a obra: a interação entre logos e ergon 35 .

$\mathrm{Na}$ verdade, refletimos ou fazemos propostas corretamente sobre os assuntos e não supomos que os discursos prejudicam as ações, mas sim que aprendemos

35 Vide A. Parry (1988). A tensão logos/ergon, que se traduz no conflito entre linguagem e realidade ou, se quisermos, a conceptualização humana das coisas e a forma como as coisas são em si mesmas, atravessa de um modo geral a obra de Tucídides e, de um modo particular, os discursos. Recorda-nos o estatuto semiótico do discurso, na sua condição de dizer o real sem ser o real ou sendo outro real. O historiador ateniense, no prólogo metodológico, divide o seu trabalho em duas categorias - logos e ergon, discursos e ações - os quais definem as duas categorias da experiência histórica. Por sua vez, Parry constata que estas duas categorias relacionam-se com outras duas: erga diz respeito à guerra; logos refere-se à escrita da história. Tucídides manifesta consciência de que logos, sendo o que o homem pensa e diz, é também uma força vital no ato da guerra; não só porque as palavras dos homens afetam a realidade, mas porque o historiador vê a linguagem como um esforço para organizar e controlar o mundo exterior. 
antecipadamente através das palavras, de preferência, antes de chegar ao que temos de fazer (Thuc. 2.40.2) ${ }^{36}$.

Os discursos não só não são entraves para as ações como auxiliam nas deliberações prospetivas. Onde reside então o problema da oratória? Péricles vai identificá-lo, secundando as críticas de Tucídides no prólogo metodológico ${ }^{37}$.

E que isto não é pompa retórica [de palavras] própria do momento, mas antes a verdade dos factos, prova-o o próprio poderio da cidade conseguido a partir destas qualidades [antes enunciadas]. Apresentando este poderio com grandes provas e não sem testemunhos, impressionaremos os homens de agora e os que hão de vir, e não precisamos nada nem de um Homero que nos elogie nem de qualquer outro que com seus versos nos deleitará no momento mas cuja manipulação dos factos a verdade deitará abaixo; nós, porém, tendo forçado todo o mar e toda a terra a tornarem-se acessíveis à nossa audácia, deixámos em todo o lado memoriais eternos dos nossos infortúnios e dos nossos êxitos (Thuc. 2. 41. 2, 4) ${ }^{38}$.

Através de Péricles, Tucídides recoloca logos e ergon em confronto. As provas (semeia) e a não ausência de testemunhos (amarturon) da grandeza de Atenas falam por si, prescindindo de qualquer engrandecimento retórico-poético, metonimicamente representado em Homero, o poeta por antonomásia. O discurso é efémero; os memoriais ${ }^{39}$, os testemunhos e a verdade dos factos permanecem e prevalecem sobre o prazer e a beleza

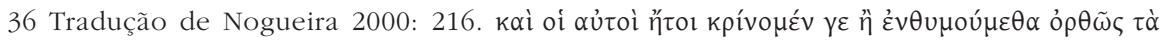

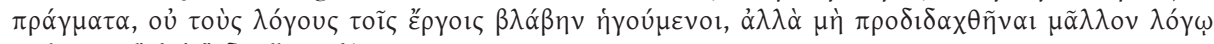

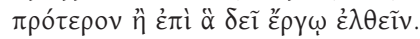

37 Sobre a correspondência entre a oração fúnebre de Péricles e o prólogo metodológico de Tucídides, vide o estudo de Grethlein de 2005 e 2013.

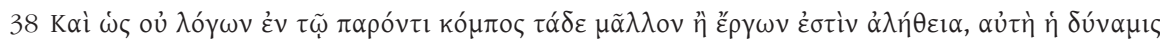

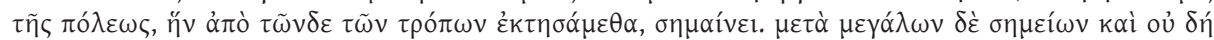

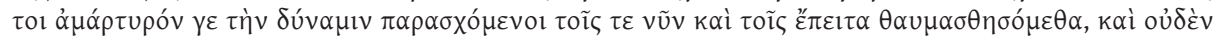

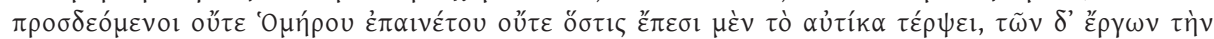

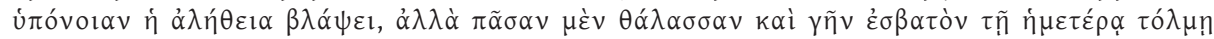

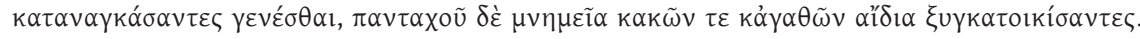

39 Não sabemos propriamente a que mnemeia se refere Péricles. Ober (1993: 93) coloca a hipótese de Péricles apontar para os monumentos e edifícios públicos erguidos durante o seu mandato, nomeadamente o Pártenon e demais templos, que seriam um sinal visível hic et nunc do poder ateniense. 
momentânea de palavras sem consistência empírica. Em sintonia com a voz narrativa do historiador, a defesa e enaltecimento da verdade feita por Péricles implica a depreciação da Oratória e da Poesia. Esta sobreposição de vozes tem suscitado imensas dúvidas acerca da veracidade do epitaphios $\log O S^{40}$. Quando adiante, já depois da funesta peste que leva Péricles a cair em desgraça perante os seus concidadãos, Tucídides tece o panegírico do estadista recém-falecido, enaltece a sua capacidade de liderança e a sua autoridade, num tom que pende mais para a oligarquia do que para a democracia, colocando em destaque a sua recusa em falar para agradar (bedone) ao povo, não hesitando em opor-se às massas populares.

[...] controlava a multidão livremente, e dirigia-a mais do que era dirigido por ela, porque, não tendo obtido o poder de forma não legítima, não falava para agradar às pessoas, mas apoiado na sua reputação, podia opor-se à cólera das pessoas. [...] na palavra era uma democracia, na prática era o governo do primeiro cidadão (2. 65. 8, 9) ${ }^{41}$.

Nesta espécie de elogio fúnebre, Tucídides sublinha uma das características da personalidade do líder ateniense que melhor sintoniza com os valores que ele próprio defendeu no seu discurso, a saber, a capacidade de resistir à retórica demagógica. Assiste-se, por conseguinte, a uma montagem muito coerente do ethos de Péricles, conseguida através da consonância entre o conteúdo metacrítico do epitaphios logos e esta espécie de epitáfio.

A dicotomia ergon/logos aparece agora aplicada ao próprio conceito de democracia: já que na teoria ou em palavras era uma democracia, mas na prática era o governo do líder.

O conceito de democracia, que já antes havia estado na mira de Tucídides, levantando algumas interrogações quanto à sua abrangência social em

40 Ficou famosa a análise crítica de Loraux 1986.

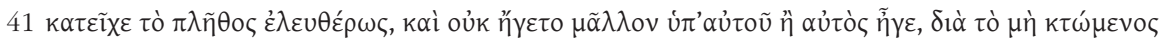

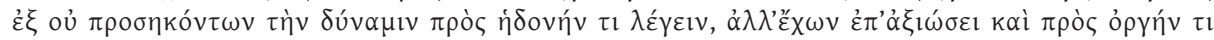

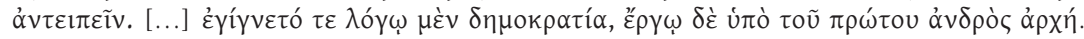


confronto com a isonomia ${ }^{42}$, é fortemente questionado no combate oratório entre Cléon e Diódoto, desta feita pelo ataque e defesa de um dos seus princípios fundamentais: a isegoria. O princípio de igualdade no acesso ao uso da palavra na assembleia pública e nos tribunais constituía uma das traves mestras da experiência democrática; porém, não raras vezes, colhia o favor dos ouvintes aquele que falava melhor ou que era mais eloquente, sobrepondo-se o poder retórico ao poder político, o ajuste das palavras à justiça dos atos, o sucesso do discurso ao sucesso da própria polis, o interesse pessoal ao interesse comum. Tanto assim era que se gerou uma nova classe profissional, os Sofistas, cuja missão era ensinar a eloquência aos seus clientes, para que estes se pudessem defender bem em tribunal ou brilhar nas assembleias públicas. A logomaquia entre o demagogo Cléon e o moderado Diódoto dá ao historiador a possibilidade de montar a mais extensa, elaborada e memorável reflexão em torno da complexa e problemática relação entre retórica e democracia ${ }^{43}$.

Cléon começa por criticar o próprio regime democrático e a forma como delibera, denunciando a volubilidade ou instabilidade dos decisores, os cidadãos da polis, que numa hora decidem uma coisa (no caso em apreço, o extermínio dos Mitileneus) e na hora seguinte, mudam de opinião:

42 "E quanto ao nome, porque não governam para poucos, mas para muitos, chama-se democracia; no que respeita à parte que cabe a cada um, há igualdade, pelas leis, para todos em relação às divergências privadas" (Thuc. 2. 37. 1). Trad. A. Nogueira 2000: 211. Ober (1993: 94-96) observa uma contradição na definição em termos de alcance e direitos sociais, mas também denota um desencontro entre o referente de politeia e o próprio significante.

43 "It is scarcely conceivable that anything like these arguments, as represented by Thucydides, could have been delivered in an actual assembly, and certainly not with the complexity, depth, and bite that characterize them in Thucydides' text" (Yunis 2013: 156). O confronto entre Cléon e Diódoto tem sido amplamente estudado e usado como caso paradigmático de debate deliberativo e discurso oratório, pelo que seria difícil apresentar aqui uma lista bibliográfica exaustiva. No entanto, salientamos o estudo clássico de Moraux 1954, Andrewes 1962, Mcleod 1983: 88-101, Ober 1998, Rocha 2008: 191-212 e o mais recente de Mader 2017. 
Muitas vezes e noutras ocasiões já eu constatei que a democracia é incapaz de governar os outros, e por maioria de razão agora que mudais de ideias acerca dos Mitileneus (Thuc. 3. 37. 1) ${ }^{44}$.

A partir de 3. 38. 2-7, o ateniense vai direto ao assunto, deduzindo um ataque à ética dos oradores e por inerência ao potencial nocivo da retórica discursiva: mostra-se surpreendido pela revogação da pena dos Mitileneus e pela perda de tempo que representa retomar a questão em Assembleia; questiona-se também com admiração sobre quem virá defender a causa dos sentenciados contra os interesses dos atenienses, considerando que tal orador, ou confiado na sua eloquência (legein pisteusas) ou atraído pelo lucro (kerdei epairomenos), tentará distrair-vos forjando um belo aparato de palavras $^{45}$. Se Tucídides parece não demonstrar grande simpatia por Cléon, pelo menos neste ponto as palavras poderiam ser suas ${ }^{46}$. Também as seguintes parecem ter a sua autoria. Cléon prossegue a diatribe a golpes violentos, desta feita contra o auditório e o seu gosto por este tipo de combates oratórios:

A cidade com este tipo de competições atribui os prémios aos outros e suporta ela os riscos. Os culpados sois vós, maus organizadores de competições oratórias, vós que estais acostumados a ser espetadores de discursos e ouvintes dos factos, que examinais os factos que podem vir a acontecer como sendo possíveis com base no que dizem os bem-falantes, e, por outro lado, os acontecimentos que já se passaram com base no valor que lhes é atribuído por um discurso bonito, confiando mais no que ouvistes do que no que vistes. Vós, os melhores a deixarem-se enganar pela originalidade de um discurso [...], escravos que sois sempre das novidades, cheios de desprezo pelas coisas habituais; e acima de tudo cada um de vós desejando poder discursar ou, se não, competir com os que discursam acerca do mesmo tipo de questões [...] procurando, por assim dizer, uma realidade diferente da nossa, mas sem pensar suficientemente na que está à nossa frente: em suma, vencidos pelo

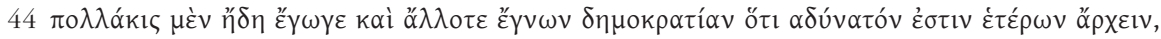

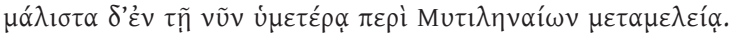

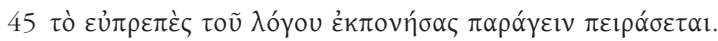

46 Acerca desta sobreposição de vozes, vide Mader 2017: 4-7. 
prazer de ouvir e mais parecidos com os espetadores sentados em certames de sofistas do que com homens que deliberam acerca dos problemas da cidade (Thuc. 3. $38.3-7)^{47}$.

Os temas, as censuras e as tensões já antes expressas por Tucídides e Péricles aparecem condensadas na argumentação de Cléon: uma crítica generalizada ao debate público, aos discursos epidícticos e ao gosto dos atenienses por este tipo de competições orais (refletida em termos como agonon, agonothetountes, antagonizomenoi); a tensão ouvido-visão e ergon-logos, bem espelhada no quiasmo espetadores de discursos e ouvintes dos factos; a censura do discurso bonito, mas falso, e da eloquência falaciosa; a falta de competência dos ouvintes para deliberar por serem presas fáceis da pompa retórica e se deixarem facilmente influenciar pelo efeito persuasivo e hedónico das palavras, o qual conduz à perceção acrítica do passado e a más deliberações sobre o futuro. Inédita é aqui a referência à paixão dos ouvintes pela novidade e pela originalidade e a repulsa pelo que é habitual, assim como a alusão ao potencial alienador ou evasivo da epideixis sofística, que leva a trocar o real pelo imaginário ou utópico.

Cabe a Diódoto o papel de antagonista neste drama verbal deliberativo, saindo em defesa da oratória e da reputação dos oradores, em linha com parte do discurso fúnebre de Péricles acima analisado (Thuc. 2. 40. 2). Começando a sua intervenção em 3. 42. 2, Diódoto considera que a rapidez e a paixão são más conselheiras de uma boa decisão; quanto às palavras (logous), quem quer que defenda que elas não são as mestras dos nossos atos (didaskalous ton pragmaton), ou é ignorante ou está a defender algum interesse pessoal ${ }^{48}$. Só alguém desprovido de inteligência pode achar que há

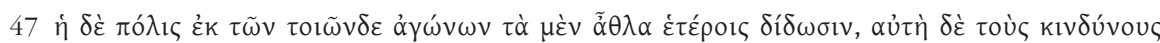

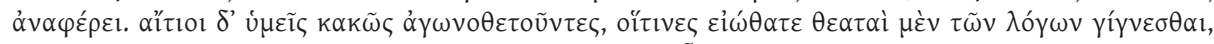

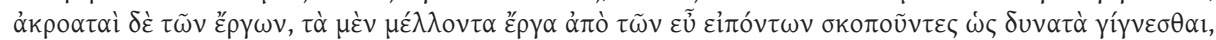

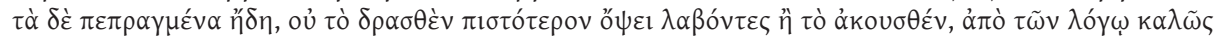

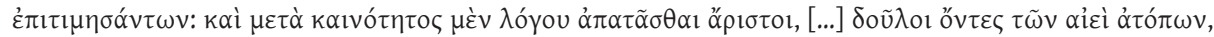

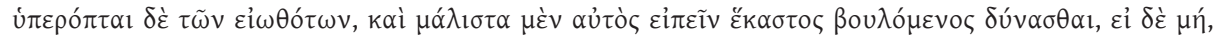

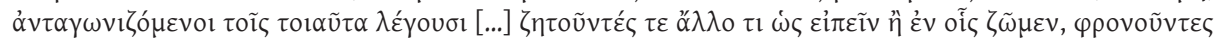

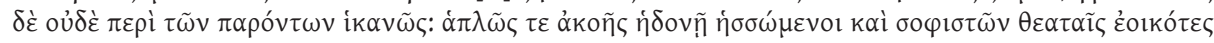

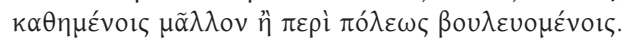

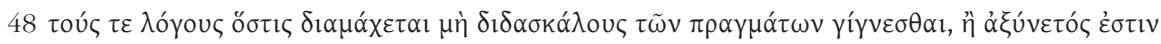

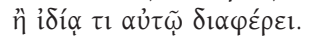


outro meio melhor que o debate oratório para explicar o futuro e desvendar o que ainda não é claro $^{49}$; só alguém movido por interesses privados pode persuadir a que se tomem medidas vergonhosas, não se inibindo de, para isso, caluniar quem quer que se lhe oponha. No entanto, mais vale acusar um orador (epideixin tina) - orador aqui identificado com o especialista em oratória epidíctica - de ser incompetente ou ignorante (amathian) do que de ser corrupto, porque movido por dinheiro (epi chremasi). É que vale mais ter reputação de mau orador, por falta de eloquência, aqui referida como falta de persuasão (o me peisas), do que de pessoa desonesta (adikoteros). De facto, um bom orador, ou seja, alguém que sabe persuadir, expresso pelo emprego do particípio aoristo do verbo peito (peisas), se for considerado desonesto (adikias d'epipheromenes), será sempre escutado com desconfiança (bupoptos), e se falhar nas suas previsões, será não só desonesto (adikos) como ignorante (axunesias). Nestas circunstâncias, é a cidade que sai a perder, porque o medo priva-a de conselheiros ${ }^{50}$. A cidade não deve nem premiar excessivamente o orador cujos conselhos se revelaram frequentemente acertados (eu bouleuonti) nem punir ou tratar com desconsideração um orador menos afortunado (ton me tuchonta gnomes).

É que, assim, poderia acontecer que o orador muito bem sucedido falasse contra o seu próprio pensamento para agradar e alcançar honras ainda maiores, e do mesmo modo um mal sucedido procurasse seduzir a multidão tentando agradar-lhe (Thuc. 3. 42.6$)^{51}$

Se Cléon censurava o auditório por se deixar enganar e influenciar pela retórica da linguagem, Diódoto faz incidir a sua crítica noutros pontos do seu comportamento, desde logo no facto de não darem ouvidos aos bons conselhos de um orador sobre o qual tenha recaído a suspeita de corrupção (Thuc. 3. 43.1). Lembremo-nos de que o próprio Diódoto tinha sido subrepticiamente acusado de má conduta por Cléon, numa estratégia suja de

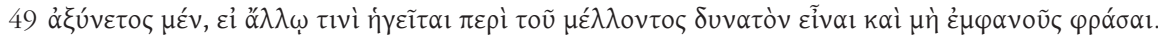

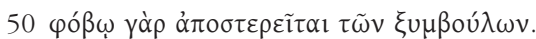

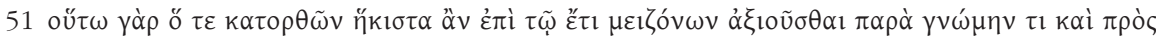

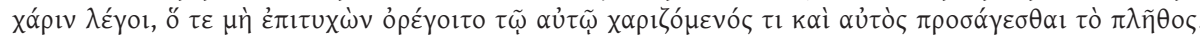


denegrir o adversário e desse modo tirar-lhe credibilidade ${ }^{52}$. O clima de suspeita generalizada e de maus juízos que se abateu sobre os oradores gera uma situação paradoxal: os bons veem-se obrigados a mentir e a enganar para serem levados a sério; caso contrário, se agirem de forma desinteressada e aparentemente honesta, levantam sobre si suspeitas iníquas. Então, há que agir com dolo para ser considerado honesto:

Está instituído que os bons conselhos proferidos sem rodeios não levantam menos suspeita do que os maus, a ponto de ser necessário que tal como aquele que quer persuadir a multidão com conselhos terríveis o faz com recurso ao engano, também aquele que quer apresentar os melhores conselhos se vê obrigado a tornar-se digno de crédito mentindo. Por causa destas manigâncias é que só nesta cidade é impossível agir [bem] com transparência sem ser através do dolo; já que, se alguém quer dar às claras algo de bom, gera desconfiança sobre de que modo oculto tirará daí proveito (Thuc. 3.43.2-3) 53 .

O papel dos oradores no estado democrático é fundamental e indispensável e, para que não haja dúvidas, Diódoto termina o proémio da sua intervenção (Thuc. 3. 43. 3-5) defendendo a sua missão na cidade, sobretudo em matérias extremamente sensíveis como a que estava em causa, considerando que estes sabem avaliar melhor, sabem ver mais longe e são mais responsáveis do que os ouvintes, presas fáceis da retórica discursiva. A propósito da irresponsabilidade dos que tomam decisões, acrescenta de forma apotegmática: se na verdade o que persuade e o que se deixa persuadir fossem prejudicados de igual maneira, seríeis mais sensatos a tomar decisões (Thuc. 3. 43. 5)54.

52 O emprego de expedientes judiciais como a calúnia (diabole), com vista a desprestigiar o adversário, é aqui muito clara. Trata-se de uma contaminatio do discurso jurídico. Vide Iglesias-Zoido 2011: 61 .

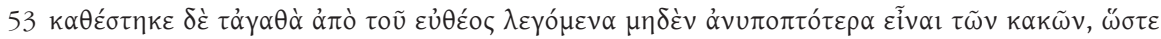

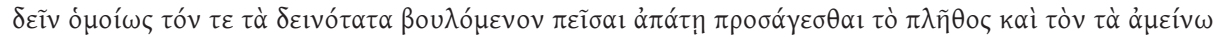

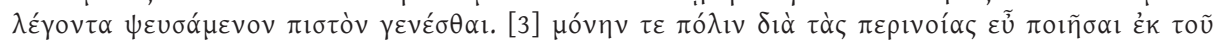

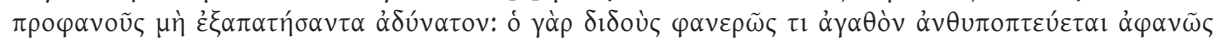

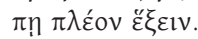

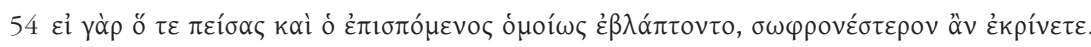




\section{CONCLUSÃO}

Tucídides (enquanto narrador autodiegético), Péricles, Cléon e Diódoto constituem uma polifonia de vozes críticas contra o uso perverso da retórica democrática. Em causa está o impacto prejudicial da oratória na tomada de decisões e a atuação de alguns políticos em democracia, os que agem e falam para agradar aos cidadãos e não em nome do proveito maior da cidade. Assim, independentemente das nuances que conferem singularidade a cada uma das intervenções supramencionadas, estas vozes convergem numa tónica dominante que dá consistência ao pensamento meta-histórico de Tucídides: o desejo de verdade; a crítica ao auditório e à receção não comprovada da informação; a manipulação do auditório por parte dos oradores, feita através do uso negativo do poder retórico da linguagem; a tendência para adoçar, embelezar e engrandecer os discursos oratórios em detrimento da exposição realista, verdadeira e fundamentada dos factos. Deste modo, é contra a oratória efémera e capciosa e contra os oradores falazes que Tucídides efetivamente se mede, apresentando como antídoto a sua investigação rigorosa e apoiada em provas, cujo valor científico a alça a um estatuto de universalidade e validade imperecíveis. Por outras palavras, para além de oferecer uma crítica à política democrática, Tucídides indica que tal sistema político beneficia com a aplicação de uma metodologia rigorosa como a sua.

Não faltam textos para engrossar a crítica ao estatuto maleável e ambivalente da retórica linguística em âmbito democrático. Obviamente, não seria possível analisá-los todos aqui no curto espaço de um artigo55.

55 Convidamos o leitor interessado a passar por Thuc. 3. 82, 4. No contexto da stasis, o historiador mostra a sua repugnância pelos efeitos desastrosos da guerra civil não só no plano físico e material, mas no nível da própria linguagem, referindo a mudança do sentido convencional das palavras para as ajustar às necessidades: audácia irracional passou a significar coragem fiel; hesitação prudente, refinada cobardia; moderação é considerada falta de coragem; visão global das coisas, incompetência; querer decidir com segurança era entendido como desculpa de bem-falante, etc. Em 5. 85. 1, no quadro da embaixada ateniense aos Mélios para negociarem a paz, os Mélios recusam levar os atenienses diante da assembleia popular, e pedem-lhes que falem apenas aos magistrados e a alguns representantes do povo. Os atenienses denunciam a estratégia, censurando-os por impedirem o povo de ouvir "um discurso contínuo, de argumentos convincentes e irrefutáveis" que de imediato os seduziria. Vide etiam Th 5. 89. 1 e 7. 8. 2. Cf. ainda a análise e comentários de Crane 1996: 209-258. 
No entanto, de modo mais velado ou explícito, por todos eles perpassa uma preocupação fundamental: onde fica a verdade no meio da ilusão (apate) produzida pela retórica ${ }^{56}$ ? No seu estudo, Ober ${ }^{57}$ refere que a democracia ateniense dependia para o seu funcionamento de um "regime de verdade" social e político a que chama de "conhecimento democrático", o qual se caracteriza por considerar que a verdade política é dialética, por consequência, assenta mais na opinião (doxa) coletiva do que em conhecimento rigoroso. Porque os atenienses acreditavam que vigorosos debates entre os cidadãos, julgados pelas massas dos seus concidadãos, podiam prover uma política razoável para a polis, a principal preocupação das instituições democráticas fundamentais não era pronunciar discursos verdadeiros, mas antes eficazes. Nesse sentido, vimos que, para o historiador ateniense, a objetividade é incompatível com o contexto de uma competição feita em função dos aplausos do auditório, gerando em Tucídides um combate entre conhecimento democrático e conhecimento histórico, para usarmos a nomenclatura de Ober. De acordo com a lógica tucididiana, o conhecimento democrático é uma base pouco sólida para a promulgação prática ou para a deliberação interventiva. Sustentado pelas provas empíricas de uma narrativa histórica objetiva, a cadeia de raciocínios aqui exposta representa uma crítica devastadora ao sistema democrático e a um dos seus mais importantes instrumentos de trabalho: o debate oratório. No entanto, Tucídides parece ser mais moderado do que Cléon, o qual manifesta uma rejeição clara dos agonisma. O historiador evita deitar fora o bebé com a água do banho, preferindo preservar a importância da disputa oratória, conferindo-lhe para isso a credibilidade "científica" de que carece. Fá-lo por intermédio da escrita, convertendo a retórica política em retórica literária ${ }^{58}$ e do estabelecimento de uma epistemologia59. Assim, o que parece

56 "The question Thucydides implicitly poses is this: can the mass of the Athenians derive rightly policy (that is, a correct assessment of the relationship between present action and future advantage) from the rhetoric they hear? It will certainly not be a easy task" (Ober 1993: 86).

57 Ober 1993: 82-85

58 Vide Yunis 2013.

59 Epistemologia essa que, por um lado, se apresenta como uma crítica da oralidade e de convenções populares de exposição oral, tidas como obstáculo à seriedade, à exatidão 
configurar um desajuste entre forma e conteúdo ${ }^{60}$ torna-se uma demonstração empírica, que visa conferir rigor (akribeia) e credibilidade (pistis) à oratória. Daí, haver quem sustente ser a epistemologia de Tucídides uma resposta ao relativismo da sofística de Protágoras e de Górgias ${ }^{61}$.

Por fim, há o problema do auditório, presa fácil da manipulação retórica e dos interesses ocultos dos oradores. Por intermédio de Cléon e Diódoto, Tucídides manifesta pouca confiança e muita preocupação com este tipo de governo assente em votações populares. A palavra, na ágora democrática, tinha uma eficácia ilocutória declarativa, na medida em que os atos de fala interferiam na realidade e criavam novas praxeis. Como podem os ouvintes distinguir a verdade da falsidade dos discursos ou o interesse pessoal do interesse coletivo? Tucídides parece sugerir que a solução passa por dar ouvidos apenas a indivíduos que se apresentem bem informados, esclarecidos, devidamente fundamentados e sem necessidade de protagonismo ou de qualquer vantagem material. Nesse sentido, o próprio Tucídides e Péricles constituir-se-iam como paradigmas de ciência e política, exemplares no seu profissionalismo e na capacidade de interpretação prévia dos factos, poupando o auditório à dura e arriscada tarefa hermenêutica de procura da verdade ${ }^{62}$. No entanto, os atenienses, segundo Tucídides, não foram capazes de aprender

e à verdade; e, por outro, como um conjunto de princípios de trabalho que visam superar essas falhas. É para cumprir este propósito que ele deixa fora da sua composição histórias e outras diversões atrativas para o ouvido, que eram o trunfo do orador ou do seu antecessor, Heródoto (nunca nomeado); e recusa registar tudo o que lhe dizem, submetendo, segundo ele, a informação recebida de terceiros ao filtro da verdade e a critérios de relevância (Thuc. 1. 22. 1-3); e não expõe os seus leitores ao relativismo de múltiplas versões, numa clara demonstração de apreço pela verdade. Perseguindo a exatidão (akribeia), assume-se como o melhor juiz para avaliar a credibilidade dos informadores e apurar a validade dos diferentes testemunhos.

60 Segundo Greithlein (2013: 137), a crítica de Tucídides à democracia revela uma discrepância entre conteúdo e forma: enquanto representa uma visão crítica da democracia ateniense, a sua forma de exprimir tal criticismo assenta em recursos que são essencialmente democráticos.

61 Untersteiner 1954: 101-131; Crane 1996: 215-218. Para os sofistas de um modo geral e particularmente para Górgias ( $O$ Elogio de Helena) o laço existente entre as palavras (logoi) e os acontecimentos (erga) é meramente arbitrário; a linguagem não tem outro fim que o de persuadir e criar imagens ilusórias da realidade. Esta conceção da linguagem inviabiliza qualquer possibilidade de chegar ao conhecimento e à verdade. Vide Eire 2007.

62 'Pericles' role as a statesman mimics that of Thucydides as historian - the hard work of fact-sifting and interpretation is done in advantage by the expert, rather than being left to the assemblyman or reader" (Ober 1993: 97). 
com a ktema es aiei do seu líder. Por isso, depois da morte de Péricles, tomaram um conjunto de más decisões que conduziram paulatinamente Atenas e a democracia à ruína.

\section{BIBLIOGRAFIA:}

Andrewes, A., "The Mytilenean Debate: Thucydides 3.36-39". Phoenix 16 (2): 64-85

Arendt, H. (2006), Entre o Passado e o Futuro. Lisboa.

Aron, R. (1961), Dimensions de la conscience bistorique. Paris.

Brunt, P. A. (1993), Studies in Greek history and thought. Oxford.

Cogan, M. (1981), The human thing. Chicago and London.

Châtelet, F. (1962), La naissance de l'histoire. Paris.

Cole, T. (1986), "Le origini della retorica", QUCC 23: 7-21.

(1991), The origins of rhetoric in ancient Greece. Baltimore/London.

Corcella, A. (2006), "The New Genre and its Boundaries: Poets and Logographers", in in Rengakos, A. and Tsakmakis, A. (eds.), Brill's Companion to Thucydides. Leiden/Boston, 33-56.

Crane, G. (1996), The blinded eye. Thucydides and the new written word. Boston Way, Lanham, Maryland.

Detienne, M. (2006), Les maîtres de vérité dans la Grèce archaïque. Paris.

Eire, A. L. (2007), "Un mito de la retórica de Górgias", in J. Bañuls et allii (eds.), O mito de Helena: de Tróia à actualidade, vol. I, Coimbra: 213-253.

Finley, J. H. (1967), Three essays on Thucydides. Cambridge/Massachusetts.

Flory, S. (1990), "The Meaning of to mythodes (1.22.4) and the Usefulness of Thucydides' History", Classical Journal 85: 193-208.

Gomme, A. W. (1954), The Greek attitude to poetry and bistory. Berkeley and Los Angeles.

Grethlein, J. (2005), "Gefahren des logos. Thukydides' 'Historien' un die Grabrede des Perikles". Klio 87: 41-71

. (2010), The Greeks and their Past. Poetry, Oratory and History in the Fifth Century BCE. Cambridge.

(2013), "Democracy, Oratory, and the Rise of Historiography in Fifth-century Greece", in J. P. Arnason; K. A. Raaflaub; P. Wagner (eds.), The Greek Polis and the Invention of Democracy: A Politico-cultural Transformation and Its Interpretations. West Sussex, 126-143. Hammond, N. G. L. (1973), "The Universal and the Particular in the Speeches of Thucydides", in Ph. Stadter, The Speeches in Thucydides. Chapell Hill.

Hansen, M. H. (1993), "The Battle Exhortation in Ancient Historiography: Fact or Fiction?", Historia 42:161-80.

Hartog, F. (2005), Évidence de l'histoire. Paris.

Hornblower, S. (1987), Thucydides. London.

(1991). A Commentary on Thucydides, vol. I. Oxford.

Hunter, V. (1982), Past and process in Herodotus and Thucydides. New Jersey.

Iglesias-Zoido, J. C. (2006), "El sistema de engarce narrativo de los discursos de Tucídides", Talia dixit 1: 1-28. 
(2007), "The Battle Exhortation in Ancient Rhetoric". Rhetorica 25: 145-165.

(2008) "La Historia de Tucídides: los discursos", in Sanz, M. \& Hualde, P. (eds.), La Literatura griega y su tradición. Madrid, 185-228.

(2008a) "La argumentación en las arengas militares de Tucídides", Antiquité Classique

77: 19-40.

(2011), El Legado de Tucídides en la Cultura Occidental - Discursos e Historia. Coimbra.

Jones, H. S.; Powell, J. E. (eds.), (1942, reimp. 1963), Thucydidis. Historiae. 2 vols. Oxford.

Kemos, A., (1994), "The influence of Thucydides in the modern world", in http://www.hri.org/por/ thucydides.html. Consultado a 9 de janeiro de 2015.

Koselleck, R. (1990), Le futur passé: contribution à la sémantique des temps historiques. Paris.

Lanni, A. (2013), "Law and Democracy in Classical Athens", in J. P. Arnason; K. A. Raaflaub; P. Wagner (eds.), The Greek Polis and the Invention of Democracy: A Politico-cultural Transformation and Its Interpretations. West Sussex, 163-180.

Lavency, M. (1964), Aspects de la logographie judiciaire attique, Louvain.

Lendon, J. E. (2017), "Battle Description in the Ancient Historians II: Speeches, Results and Sea Battles", Greece and Rome 64: 145-167.

Loraux, N. (1986), The Invention of Athens: The Funeral Oration in the Classical City. Cambridge MA. Macleod, C. (1975), "Rhetoric as History: Thucydides 6.16-18", Quaderni di Storia 2, 39-65.

(1983), Collected Essays. Oxford.

Mader, G. (2017), "Demagogic Style and Historical Method: Locating Cleon's Mytilenean Rhetoric (Thucydides 3.37-40)", Rhetorica 35: 1-23.

Mara, G. (2008), Classical political philosophy and the limits of democracy. New York.

Marincola, J. (1997), Authority and tradition in ancient bistoriography, Cambridge. (2005), "Agonisma”, LHGEL 1.

(2008), "Speeches in Classical Historiography", in A Companion to Greek and Roman Historiography. Oxford, 118-132.

Meier, C. (1980), Die Entstebung des Politischen bei den Griechen. Frankfurt am Main.

(1987), "Historical Answers to Historical Questions: The Origins of History in Ancient Greece", in D. Boedeker (ed.), Herodotus and the Invention of History (Arethusa 20). Baltimore, 41-57.

Moles, J. L. (2003), "Truth and Untruth in Herodotus and Thucydides", in Ch. Gill e T. P. Wiseman (eds.), Lies and Fiction in the Ancient World. Liverpool, 88-121

Moraux, P. (1954), "Thucydide et la rhétorique", LEC 22: 3-23.

Morrison, J. (2006), "Interaction of Speeche and Narrative in Thucydides", in Rengakos, A. \& Tsakmakis, A. (eds.), Brill's Companion to Thucydides. Leiden/Boston, 251-278.

Nicolai, R. (2001), "Thucydides' Archaeology between Epic and Oral Traditions", in N. Luraghi (ed.), The Historian's Craft in the Age of Herodotus, Oxford, 263-285.

Nogueira, A. (2000), A filosofia do poder. Nomos e physis e a lei do mais forte em Tucídides (tese policopiada). Faro.

Ober, J. (1993), “Thucydides' Criticism of Democratic Knowledge”, in R. M. Rosen; J. Farrel (eds.), Nomodeiktes: Greek Studies in Honour of Martin Ostwald. Ann Arbor, 81-98.

Ober, J. e Hedrick C. (1996), Demokratia: A Conversation on Democracies, Ancient and Modern. Princeton.

Ober, J. (1998), Political Dissent in Democratic Athens: Intellectual Critics of Popular Rule. Princeton. Parry, A. M. (1988), Logos and Ergon in Thucydides. Salem, New Hampshire.

Raaflaub, K. (2006), "Thucydides on Democracy and Olygarchy”, in A. Rengakos and A. Tsakmakis 
(eds.), Brill's Companion to Thucydides. Leiden, 189-222.

Rengakos, A. \& Tsakmakis, A. (eds.), (2006), Brill's Companion To Thucydides. Leiden.

Rocha, S. L. R. (2008), Logos, Writing and Persuasion in Thucydides' History. London: PhD thesis submitted to the University of London.

Romilly, J. (1956), Histoire et raison chez Thucydide. Paris.

(1990), La construction de la verité chez Thucydide. Paris.

(2005), L'invention de l'bistoire politique chez Thucydide. Paris.

Rusten, J. (ed.), (2009), Oxford readings in Classical Studies. Oxford.

Scardino, C. (2007), Gestaltung und Funktion der Reden bei Herodot und Thukydides. Berlin.

Sebastiani, B. B., (2017), "O problema da verdade em Tucídides”, in Fracasso e verdade na recepção de Políbio e Tucídides. Coimbra, 75-92.

Sinclair, R. K. (1988), Democracy and Participation in Athens. Cambridge.

Soares, M. (2014), História e ficção, em Paul Ricoeur e Tucídides, Fundação Eng. António de Almeida, Porto. https://digitalis.uc.pt/pt-pt/node/116459.

Swain, S. (1993), "Thucydides 1.22.1 and 3.82.4", Mnemosyne 46: 33-45.

Tsakmakis, A. (2006), "Leaders, Crowds, and the Power of the Image: Political communication in Thucydides", in A. Rengakos and A. Tsakmakis (eds.), Brill's Companion to Thucydides. Leiden/Boston, 161-188.

Tsakmakis, A. (2017), "Speeches", in S. Forsdyke, E. Foster and R. Balot (eds.), The Oxford Handbook of Thucydides, Oxford, 267-282.

Tsakmakis, A. \& Tamiolaki, M. (2013), Thucydides between bistory and literature. Berlin/Boston.

Untersteiner, M. (1954), The Sophists, trad. ingl. K. Freeman. Oxford.

Várzeas, M. (2004), "Entre a história e a ficção. Os discursos na obra de Tucídides", Actas do Colóquio Internacional Literatura e História, vol. II. Porto, 277-282.

Wolff, H. J. (2007), "Demosthenes as Advocate. The functions and Methods of Legal Consultants in Classical Athens", in E. Carawan (ed.), Oxford Readings in the Attic Orators. Oxford, 91-115.

Woodman, A. J. (1988), Rhetoric in Classical Historiography: Four Studies. London \& Sydney.

Yunis, H. (1996), Taming Democracy. Models of Political Rhetoric in Classical Athens. Ithaca and London.

(1998), "The Constraints of Democracy and the Rise of the Art of Rhetoric", in D. Boedeker and K. A. Raaflaub (eds.), Democracy, Empire, and the Arts in Fifth-Century Athens. Cambridge/London, 223-40

(2013), "Rhetoric and Politics in Democratic Athens (Fifth and Fouth Century BCE)", in J. P. Arnason; K. A. Raaflaub; P. Wagner (eds.), The Greek Polis and the Invention of Democracy: A Politico-cultural Transformation and Its Interpretations. West Sussex, 144-161. 